\title{
CARTOGRAFIA DA DIÁSPORA ÁFRICA - BRASIL
}

\section{Cartography of the African-Brazilian Diaspora}

Prof. Dr. Rafael Sanzio Araújo dos Anjos

Universidade de Brasília

Campus Universitário Darcy Ribeiro subsolo, Asa Norte, CEP: 70910-900 - Brasilia, DF - Brasil

Tel: (+ 55 61) 31077242 - cartografia@unb.br

\section{$a_{a} \boldsymbol{a}_{a a}$}

\section{Resumo}

Uma das questões estruturais relacionada à cultura africana no Brasil que continua merecendo investigação e conhecimento, está relacionada aos aspectos historiográficos e geográficos da formação e distribuição da população de ancestralidade na África do território brasileiro. O paper resgata as principais referências da diáspora África-América-Brasil e configura a expressão espacial da população afro-brasileira contemporânea. $\mathrm{O}$ pensamento social preconceituoso e o desconhecimento da população do país, no que se refere ao continente africano, continuam sendo um dos entraves estruturais para uma perspectiva real de democracia racial, assim como, a criação no setor decisório, das condições necessárias para a implementação de políticas públicas mais articuladas e eficazes.

Palavras Chave: Geografia Afro-Brasileira, Território Étnico; População de matriz africana; Cartografia Africana; Diáspora África-Brasil.

\begin{abstract}
One of the structural issues related to the African culture in Brazil that still deserves investigation and knowledge is related to the historiographic and geographic aspects of formation and distribution of the African descendent population in the Brazilian territory. This paper rescues the main references of the Africa-America-Brazil Diaspora and configures the spatial expression of the contemporary African-Brazilian population. The prejudiced social thinking and the lack of knowledge of the country's population, in what refers to the African continent are still a structural barrier to a realistic perspective of racial democracy, as well as creatiing in the decision-making sectors the necessary conditions to implementing more articulate and efficient public policies.
\end{abstract}

Key Words: African-Brazilian Geography; Ethnic Territory; African matrixed population; African Cartography; Africa-Brasil Diaspora.

\section{Resumen}

Una de las cuestiones estructurales relacionada a la cultura africana en Brasil que continua mereciendo investigación y conocimiento, está relacionada a los aspectos historiográficos y geográficos de la formación y distribución de la población de ancestralidad en la África del territorio brasileño. El paper rescata las principales referencias de la diáspora África-América-Brasil y configura la expresión espacial de la población afro-brasileña contemporánea. El pensamiento social prejuicioso y el desconocimiento de la población del país, en lo que se refiere al continente africano, continúan siendo uno de las trabas estructurales para una perspectiva real de democracia racial, así como, la creación en el sector de decisión, de las condiciones necesarias para la implementación de políticas públicas más articuladas y eficaces.

Palabras Clave: Geografía Afro-Brasileña, Territorio Étnico; Población de matriz africana; Cartografía Africana; Diáspora África-Brasil. 


\section{INTRODUÇÃO}

A África é o continente mais importante no suporte e na manutenção da estruturação do mundo nos últimos cinco séculos, particularmente na formação do Novo Mundo, a América. O Brasil, por sua vez, é a unidade política contemporânea que registra as maiores estatísticas de importação forçada de contingentes populacionais africanos ao longo dos séculos XVI a XIX. Dessa forma, o território africano é um componente fundamental para uma compreensão mais apurada das questões que envolvem o papel da população de ascendência africana na sociedade brasileira. Por isso, o Brasil continental, plurirracial, multicultural e com uma historicidade em processo de reconstrução e uma diversidade étnica com conflitos, tem ainda, o desafio de assumir decisivamente a nação multiétnica resultante destes séculos de "conivência" com a África. Estes são pontos estruturais que preconizam a busca de equilíbrio na sociedade brasileira e no seu território e, sobretudo um tratamento ético. Por isso mesmo, se fazem necessário, interpretações mais consistentes das origens das suas populações nos primórdios da suas formações; de um melhor entendimento e representação da dinâmica desta diáspora no espaço e uma melhor configuração da sua identidade territorial ancestral.

Apesar dessa referência histórica da matriz africana presente no país, a incorporação verdadeira, o respeito e o espaço da cultura africana no Brasil, continua sendo uma das questões estrutrais do país, que ainda merece investigação, conhecimento e ação. Nesse sentido, as demandas para compreensão das complexidades da dinâmica da nossa sociedade são grandes e existem poucas disciplinas mais bem colocadas do que a geografia e a cartografia para auxiliar na representação e interpretação das inúmeras indagações desse momento histórico.

A geografia é a ciência do território e este componente fundamental, a terra, o terreiro num sentido amplo, continua sendo o melhor instrumento de observação do que aconteceu, porque apresenta as marcas da historicidade espacial; do que está acontecendo, isto é, tem registrado os agentes que atuam na configuração geográfica atual e o que pode acontecer, ou seja, é possível capturar as linhas de forças da dinâmica territorial e apontar as possibilidades da estrutura do espaço no futuro próximo. O território é na sua essência um fato físico, político, social, categorizável, possível de dimensionamento, onde geralmente, o Estado está presente e estão gravadas as referências culturais e simbólicas da população. Não podemos perder de vista que a geografia é a área do conhecimento que tem o compromisso de tornar o mundo e suas dinâmicas compreensíveis para a sociedade, de dar explicações para as transformações territoriais e de apontar soluções para uma melhor organização do espaço. A geografia é, portanto, uma disciplina fundamental na formação da cidadania do povo brasileiro, que apresenta uma heterogeneidade singular na sua composição étnica, socioeconômica e na distribuição espacial.

Os mapas, por sua vez, são as representações gráficas do mundo real, se firmam como ferramentas eficazes de interpretação e leitura do território, possibilitando revelar a territorialidade das construções sociais e feições naturais do espaço e, justamente por isso, mostram os fatos geográficos e os seus conflitos. Estes possibilitam revelar graficamente o que acontece na dinâmica do espaço e tornam-se cada vez mais imprescindíveis, por constituírem, uma ponte entre os níveis de observação da realidade e a simplificação, a redução, a explicação e de pistas para a tomada de decisões e soluções dos problemas. Não podemos perder de vista que um mapa não é o território, mas que nos produtos da cartografia estão as melhores possibilidades de representação e leitura da história do território.

Neste paper buscamos auxiliar na ampliação das informações sobre as referências territoriais dos deslocamentos seculares África-Brasil e os aspectos historiográficos da distribuição da população de matriz africana e seu rebatimento na formação do território brasileiro. Este trabalho faz parte de uma das etapas operacionalizadas no Projeto Geografia Afro-Brasileira: Educação \& Planejamento do Território, em desenvolvimento no Centro de Cartografia Aplicada e Informação Geográfica (CIGA) do Departamento de Geografia da Universidade de Brasília e na Fundação Brasil Africano. 
Com essas referências buscamos contribuir efetivamente para a ampliação do conhecimento e a continuidade das discussões, onde a questão étnico-racial no Brasil seja tratada com mais seriedade.

\section{A GEOGRAFIA DA DIÁSPORA ÁFRICA-BRASIL - UMA SÍNTESE}

O movimento histórico das grandes navegações, deve ser entendido como uma conseqüência direta do processo geográfico de dominação territorial desenvolvido, amadurecido e implementado pelo continente europeu. O horizonte geográfico das terras emersas vai ser ampliado de forma signgificativa pelos novos encontros de culturas, identidades e territorialidades. Como resultado, o mapa do mundo vai ser profundamente modificado nos séculos XV, XVI, XVII, XVIII E XIX, sobretudo pelos novos territórios a ele incorporado e as "novas" fronteiras constituídas e impostas. Este período da história dos seres humanos vai se caracterizar por uma nova fase de relações entre estes e a natureza.

Não eram somente as riquezas da África que interessavam a Europa Moderna, os seres humanos, também eram necessários aos colonizadores para o cultivo e a esploração das minas. Instaura-se assim um novo período de escravidão humana, associada à acumulação de capitais, estruturado num sistema político, jurídico e econômico que vai permitir o desenvolvimento de uma gigantesca empresa comercial, possibilitando a expansão do capitalismo. O tráfico demográfico forçado do continente africano para a América foi, durante quase quatro séculos, uma das maiores e mais rentosas atividades dos negociantes europeus, a tal ponto de se tornar impossível precisar o número de africanos retirados de seu habitat, com sua bagagem cultural, a fim de serem, injustamente, incorporados às tarefas básicas para formação de uma nova realidade. Entre 12 e 13 milhões de seres humanos africanos transportados é uma referência, apesar das pesquisas divergirem, ainda atualmente, sobre os registros quantitativos nessa diáspora africana. Entretanto, é consenso na comunidade científica que a dinâmica do tráfico trouxe problemas de despovoamento em numerosas áreas do continente.

É importante lembrar que o conceito geográfico de diáspora tem haver com a referência de dispersão de uma população e das suas matrizes culturais e tecnológicas. Ao longo da história podemos identificar a construção de territórios pela mobilidades das migrações, tanto de forma voluntária quanto das migrações forçadas. Na África, podemos caracterizar alguns destes grandes movimentos demográficos, a começar pela primeira diáspora, que corresponde ao processo espacial milenar de povoamento e ocupação do próprio continente e, posteriormente, para outras terras emersas do mundo. O fenômeno espacial que abordamos, nesta oportunidade está ligado aos séculos de deslocamentos, geralmente, denominado, "tráfico negreiro" para a América, fruto de longos períodos de migração forçada, contexto propulsor do sistema escravista e base do capitalismo primitivo.

Devemos ressaltar que foram as regiões geográficas do Brasil de interesse econômico europeu que detiveram os maiores fluxos de populações africanas escravizadas. A sequência dos mapas temáticos mostra uma representação gráfica das referências territoriais de origem na África nos quatro séculos do tráfico de populações e desestruturação de sociedades e Estados. No século XVI, a referência espacial principal são as regiões caracterizadas como Alta e Baixa Guiné. Esses foram trazidos principalmente para as regiões açucareiras de Pernambuco e Bahia, mas também, foram levados para o Maranhão e para o Grão-Pará. Os territórios africanos atingidos pelo tráfico nesse período atualmente correspondem aos limites internacionais dos seguintes países: Serra Leoa, Senegal, Guiné, Guiné-Bissau, Nigéria, Benin, Burquina Faso, Gana, Costa do Marfin, Libéria, Mali e Gâmbia. No século XVII o tráfico vai ser dinamizado na Costa de Angola, transportando povos africanos para a Bahia, Pernambuco, Alagoas, Rio de Janeiro, São Paulo e regiões do centro-sul do Brasil, e na Costa da Mina, com fluxos para as províncias do Grão-Pará, Maranhão e o território atual do Rio Grande do Norte. A antiga Costa da Mina compreende atualmente os territórios dos seguintes países: Costa do Marfin, Libéria, Burquina Fase, Mali, Niger, Congo, Gana, Togo, Benin, Nigéria e Camarões. A conhecida Costa de Angola corresponde atualmente aos seguintes 
países: Angola, Gabão, República Democrática do Congo e Guiné Equatorial. Nos séculos XVII e XVIII, vão se constituir as mais importantes e duradouras extensões territoriais das rotas do tráfico negreiro: as Costas da Mina e de Angola. É nesse período que vão ocorrer os maiores volumes de povos africanos transportados para o território brasileiro.

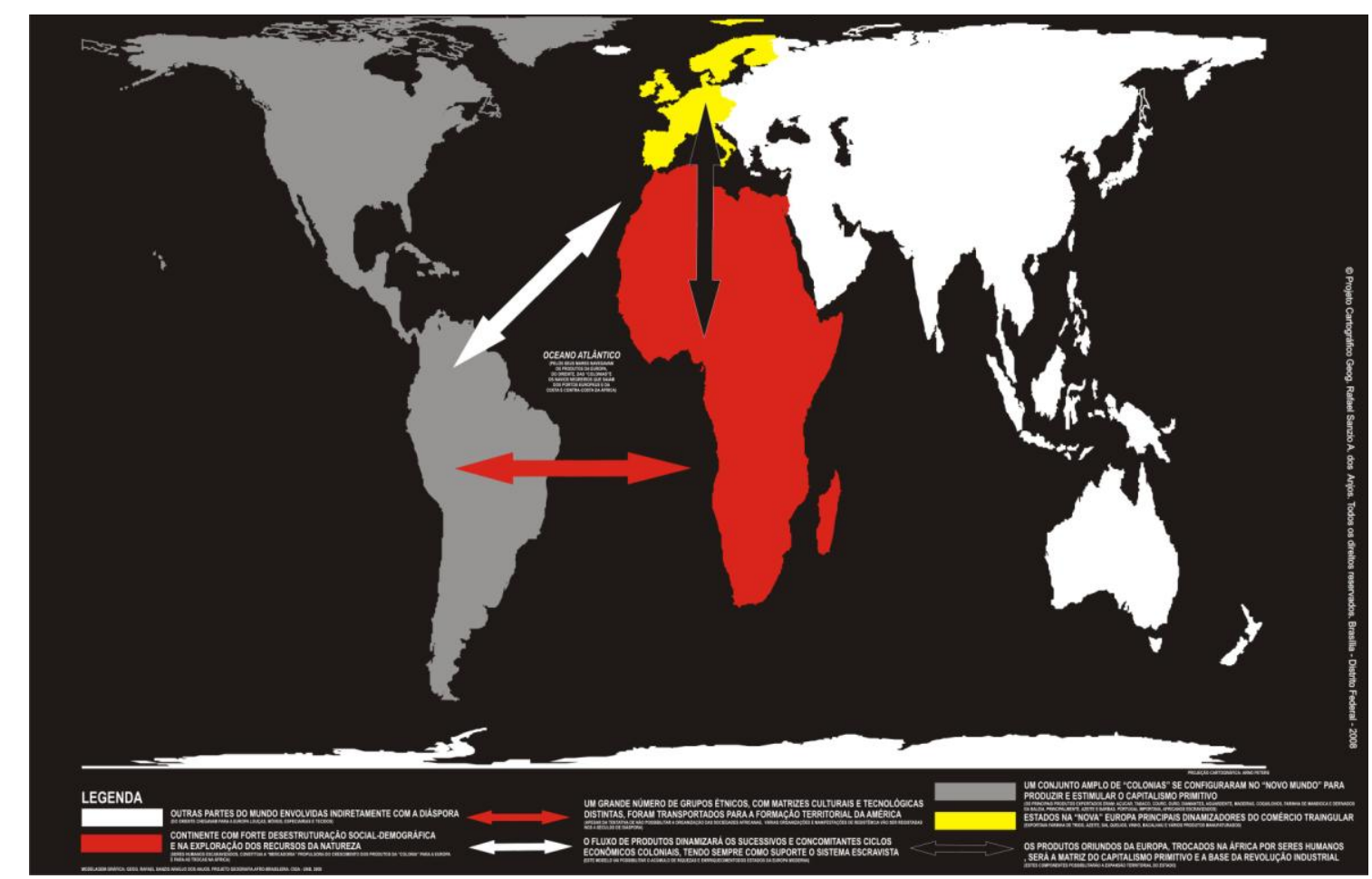

Figura 1 - Modelagem Gráfica das Estratégias dos Fluxos econômicos comerciais triangular na dinâmica da diáspora - secúlos XVI-XVII-XVIII-XIX

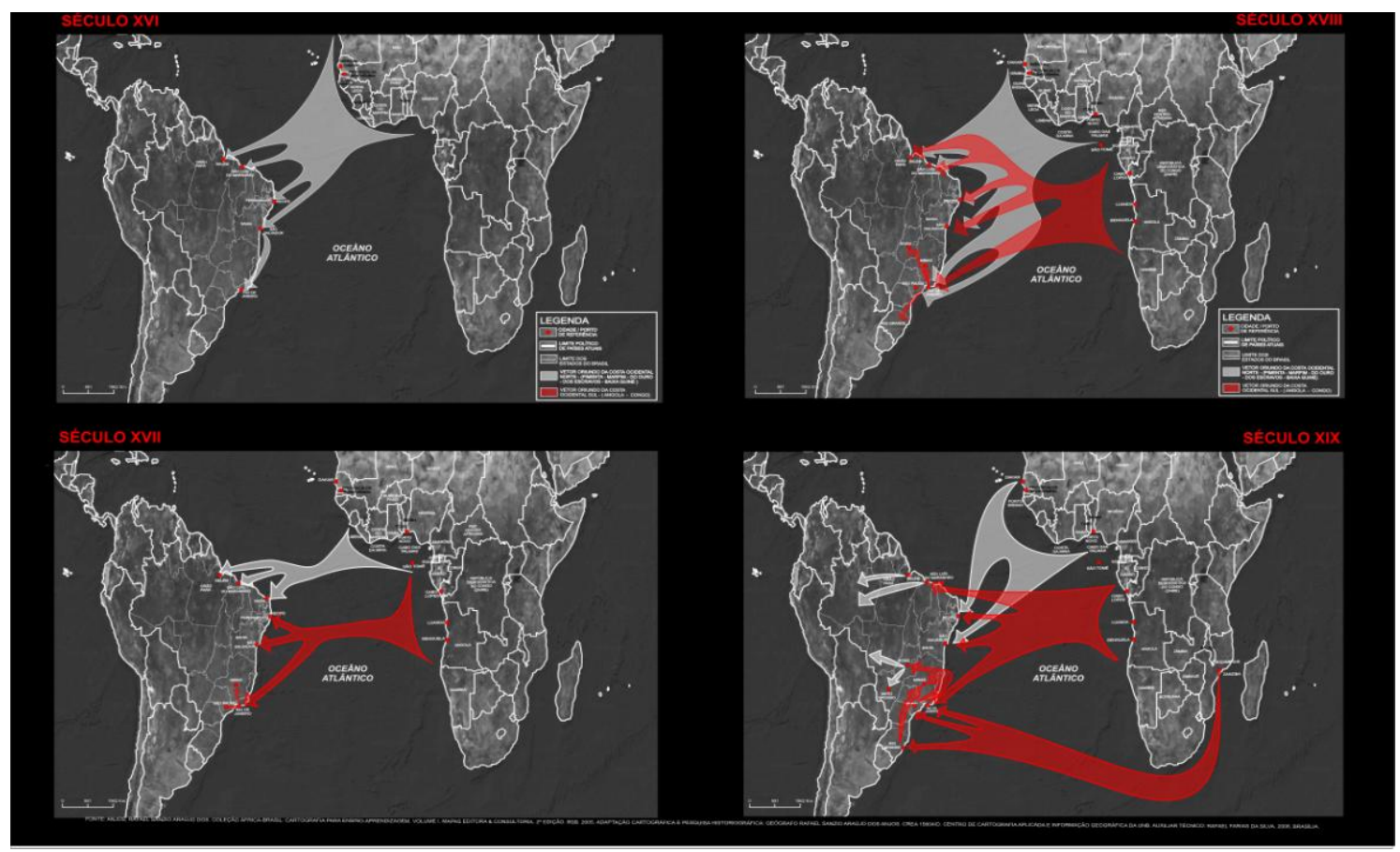

Figura 2 - Refências da dinâmica da Diáspora Africana para o Brasil e as Fronteiras atuais. 
A primeira metade do século XIX caracterizou-se pelos vários tratados visando abolir o tráfico negreiro, o que no Brasil só ocorreu efetivamente em 1850. Pelo quadro de ilegalidade e clandestinidade, os dados estatísticos dos movimentos demográficos são bem imprecisos. Esse é o período em que são desfeitas as ligações bilaterais entre os continentes africano e americano, sendo destruídas as rotas do tráfico triangular entre a América, a África e a Europa. Entretanto, o Brasil por 66 anos e os Estados Unidos por mais 90 anos, continuaram escravistas depois da independência.

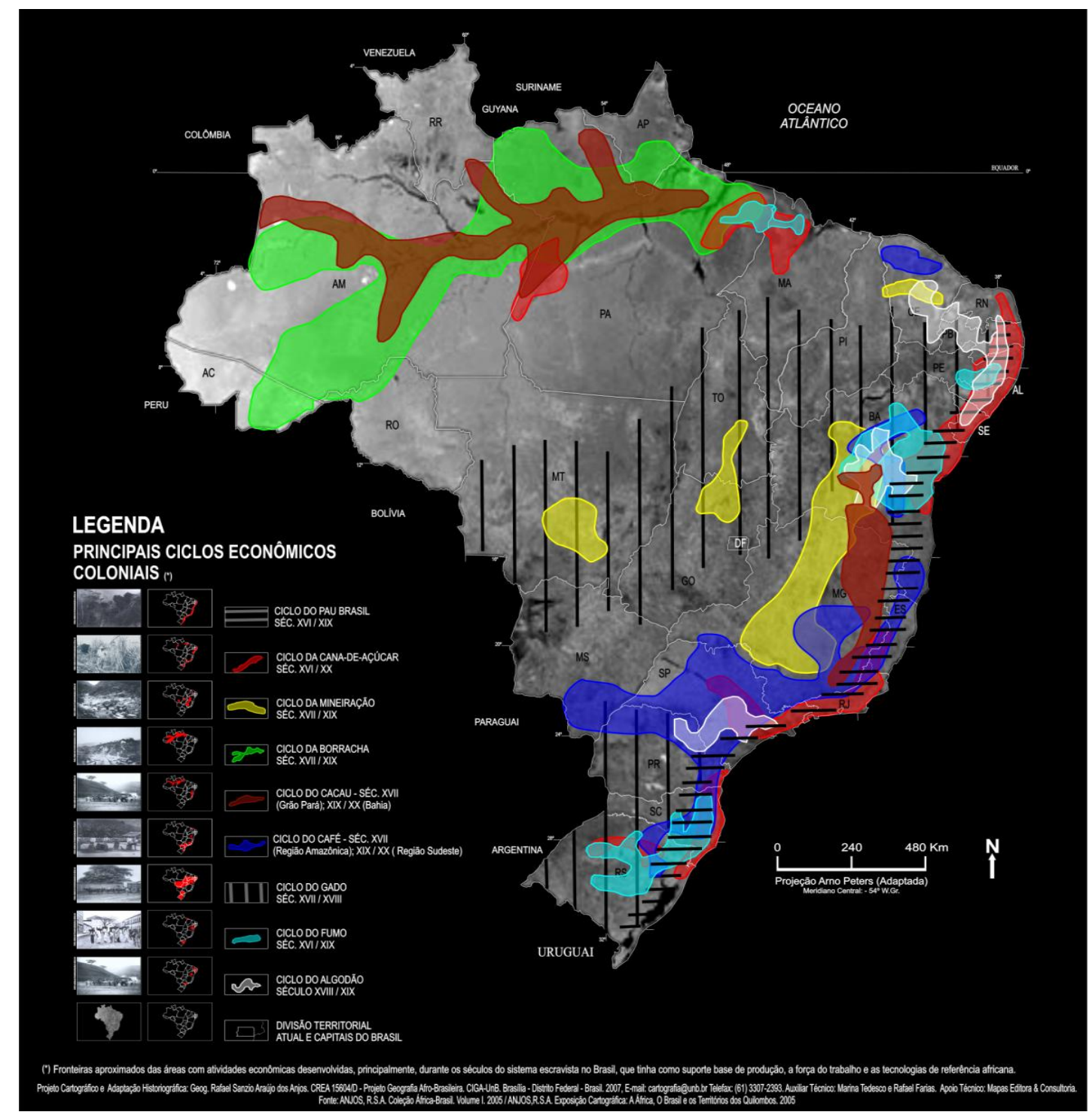

Figura 3 - Referências Territoriais dos Principais Cíclos Economicos Coloniais 


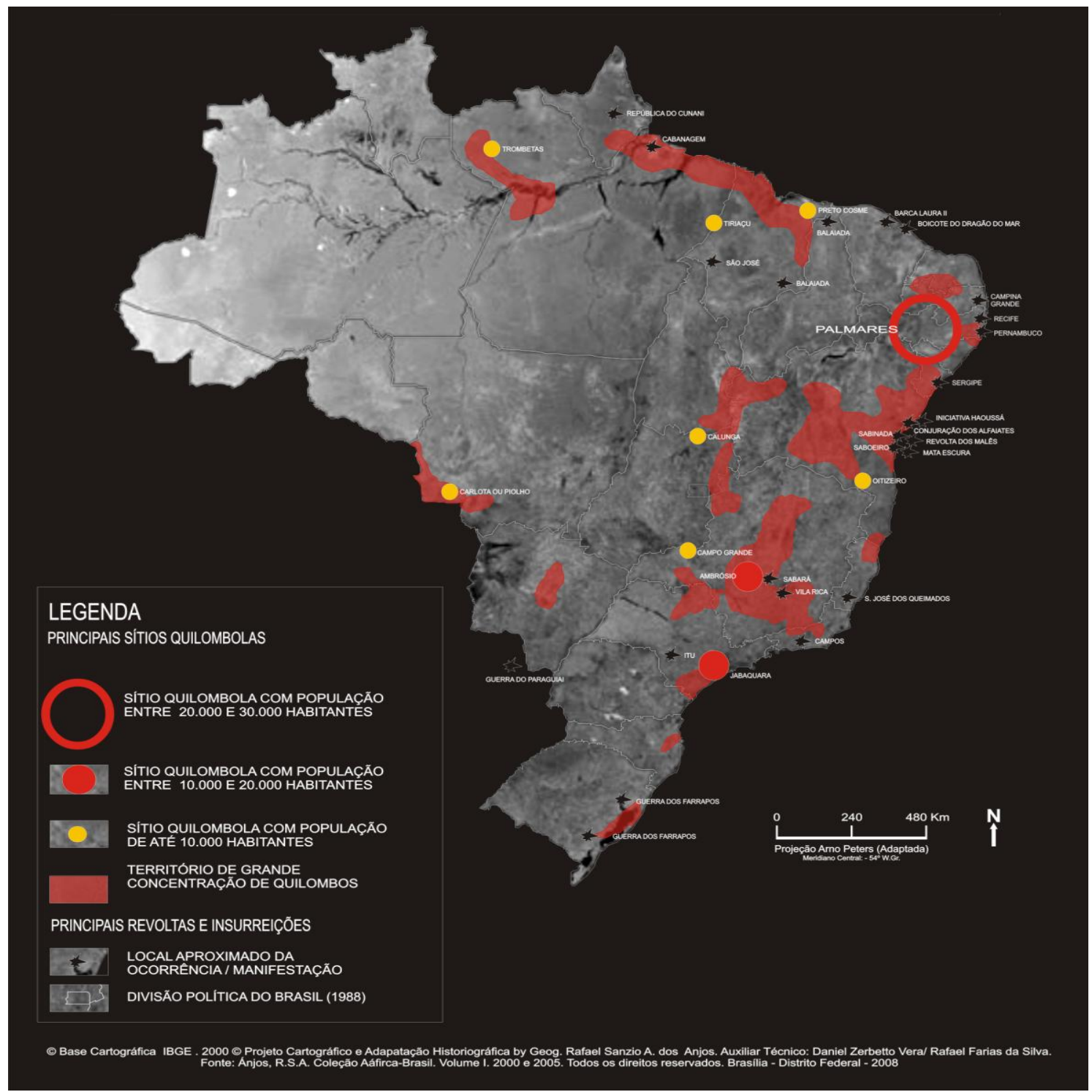

Figura 4 - Principais zonas e sítios dos quilombolas e movimentos sociais das populações africanas e dos descentes no território Brasileiro - Séculos XVI/XIX.

A manutenção dessa estruturação política, econômica e territorial por quase quatro séculos no território brasileiro e a quantidade de africanos importados até 1850, não devidamente quantificada, mostra como a consolidação da sociedade escravagista conseguiu estabilizar-se e desenvolver-se mesmo com os conflitos políticos e contradições econômicas e sociais. No "Brasil Colônia", o quilombo era uma reconstrução e elaboração concreta de um tipo de organização territorial existente na África Meridional, que apresenta variadas significações e, uma delas é um estado permanente de guerra. A palavra aportuguesada quilombo, tem sua origem na estrutura da língua bantu (kilombo) e pode ser entendido ainda, como acampamento guerreiro na floresta, o nome de uma região Administrativa de Angola, habitação no território do antigo Reino do Congo; lugar para estar com Deus na Região Central da Bacia do rio Congo e, significa, ainda, na Região Centro-Norte de Angola filho de preto que não é preto. A grande extensão dos povoados "livres", com uma forma de organização territorial de matriz africana, que vão se desenvolver nas margens brasileiras do Oceano Atlântico, têm em comum a referência de um espaço seguro e protegido, não necessariamente isolado, com igualdade de condições na maioria das relações comunitárias, de liberdade de acesso à terra e de uma base possível de ter confrontos e guerras pela manutenção do espaço "livre". Neste sentido o quilombo africano e o quilombo americano apresentam semelhanças fundamentais. 
Algumas considerações em torno das referências etnográficas da África Sub-Saariana com registros no Brasil e expressão espacial da população afro-brasileira contemporânea são temas tratadas no item a seguir.

\section{A CARTOGRAFIA DA POPULAÇÃO DE MATRIZ AFRICANA NO BRASIL - UMA TENTATIVA}

O processo de pulverização das distintas matrizes africanas nmas extensões do território colonial tinha, também, como estratégia, dificultar a organização, extinguir a língua de origem e impossibilitar a continuidade das culturas, ou seja, foram criados dispositivos reais para que as populações oriundas da África perdessem as suas referências identitárias e, por conseguinte, houvesse uma diluição da identidade étnica africana no Brasil. São "trazidos" para constituir a formação, a expansão e a ocupação efetiva do território brasileiro seres humanos: Minas, Congos, Ombundos, Bacongos, Ovibundos, Monjolos, Balundos, Jejes, Angolas, Anjicos, Lundas, Quetos, Hauças, Fulas, Ijexás, Jalofos, Mandingas, Anagôs, Fons, Ardas, dentre muitos outros, que possibilitaram o que podemos simplesmente denominar de afro-brasileiros, brasileiros de matriz africana ou população de ascendência africana. Por exemplo, as populações de matriz Bantu, com origem na África Central e os Iorubás, também denominados, Nagôs, oriundos da África Ocidental apresentam registros e características relevantes no cotidiano do "Brasil Real".

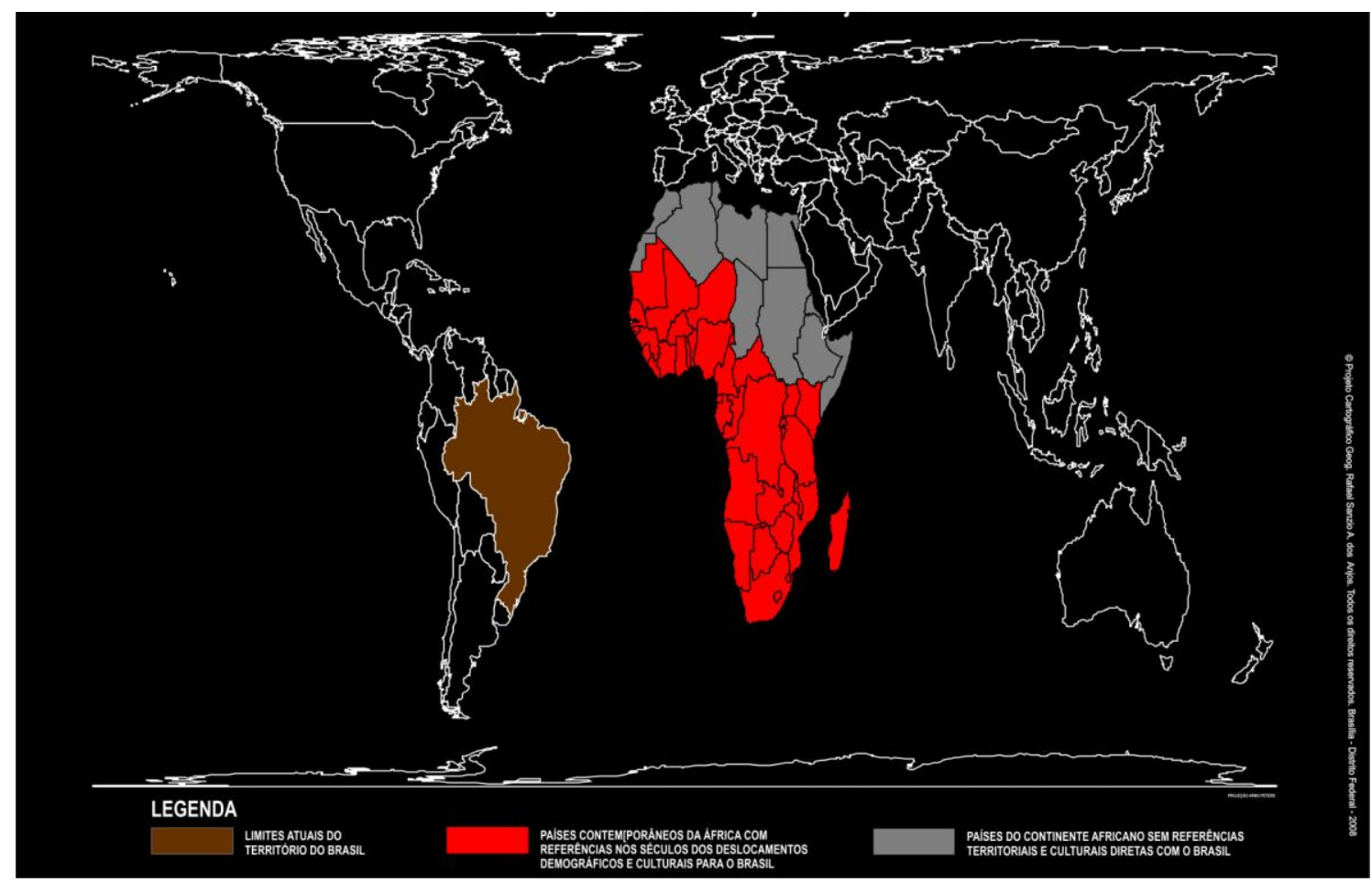

Figura 5 - O Brasil e o País da Africa com referências territóriais e culturais na diáspora.

O país sabe com clareza que, no período entre 1871 e 1920, 3.390 .000 imigrantes europeus chegaram ao país, dos quais: 1.373.000 eram italianos; 901.000, portugueses e 500.000, espanhóis. Muitos europeus no Brasil vão ocupar territórios onde já estavam estabelecidas populações africanas ou de seus descendentes, como, por exemplo, a ocupação de imigrantes italianos (1880) no sítio de Sapucaí, na região do grande Quilombo do Campo Grande, na antiga Província de Minas Gerais. É importante notar que esse número se aproxima dos quase 4.000.000 africanos que foram retirados de seu habitat natural e trazidos para o Brasil oficialmente entre 1520 e 1850 . Isso porque 
as referências espaciais, temporais e quantitativas do período clandestino do tráfico ainda estão para serem caracterizados pela historiografia brasileira.

Esse é mais um fator geográfico que colabora para a falta de uma referência ancestral de origem da população brasileira de referência africana, com interferências profundas na sua cidadania e no sentimento de pertencimento territorial. Afirmar para esse contingente que os seus antepassados foram "trazidos" do continente africano é vago, sem consistência, desrespeitoso, quando se trata de uma extensão com mais de $30.000 .000 \mathrm{Km} 2$, com contextos territoriais de centenas de antigos reinos, impérios e grupos étnicos desconhecidos da historiografia oficial do país. Essa demanda secular, que possibilitaria uma ligação espacial mais referenciada e mais precisa na África, continua sem resposta satisfatória e nem perspectiva de solução institucional.

Dessa forma, um dos grandes desafios das pesquisas territoriais destinadas à diáspora africana está no silêncio das estatísticas do tráfico e na identificação da referência territorial, portanto, do lugar de origem dos grupos de africanos que entravam no Brasil. Entretanto, tomando como premissa as indicações conhecidas dos sítios e regiões da dinâmica das rotas do tráfico no Brasil ao longo dos quatro séculos do comércio de populações africanas (Anjos, 2000); os mapeamentos realizados por Castro (2001) sobre a fala das distintas sociedades da África no Brasil e os espaços onde se instalaram os ciclos econômicos colônias (Anjos, 2006), foi possível ser feito um cruzamento dessas variáveis territoriais e inferir sobre a expressão etnográfica da África Sub-Saariana no Brasil dos séculos XVI até o XIX. Alguns contextos historiográficos e territoriais são relevantes:

1. No século XVI, que registra as primeiras levas das populações africanas para o trabalho forçado no ciclo econômico da cana-de-açúcar, no eixo territorial do Recôncavo da Bahia, ao norte de Pernambuco (onde se incluí os atuais Estados de Alagoas e Sergipe) os grupos étnicos predominantes vão ser os Bantus, da Costa de Angola, e os Jeje-Mina, da Costa da Guiné, também conhecida como Costa do Ouro, Costa do Marfim e a Costa dos Escravos. Nesse século a expansão do sistema escravista atinge o Maranhão e o Grão Pará;

2. A Costa de Angola, no século XVII, vai se caracterizar pela intensidade do tráfico, fato que vai incrementar a entrada de grande contingente de povos Bantus na região açucareira do Brasil, expandindo-se para o sudeste (Rio de Janeiro, São Paulo, Minas Gerais) e Goiaz, no centro da "Colônia". O tráfico se transferiu temporariamente para o Golfo da Guiné (Costa da Mina) e povos Jeje-Mina vão ser transportados para territórios já conhecidos como o Maranhão e o Grão-Pará, assim como, uma expansão no nordeste na direção do atual Estado do Rio Grande do Norte;

3. No século XVIII estão os registros das maiores quantidades de seres humanos do continente africano na condição de escravizados e transportados para o Brasil. Distintos grupo de líguas Bantus, como os Congos, Cabindas e Angolas, principalmente, vão se expandir pelo território brasileiro em formação, com registros em quase todos os portos da costa brasileira. Da Costa da Guiné foram trazidos para a Bahia os Nagôs-Iorubás e os Hauçás (populações sudaneses islamizados ou não);

4. O século XIX tem a referência de ser o da abolição do tráfico negreiro, entretanto, o Brasil vai continuar de forma clandestina a dinâmica demográfica de transposição de populações oriundas da Áfricas. Grupos Bantus da Costa de Angola vão ser transportados para portos no Maranhão, Pernambuco, Rio de Janeiro, São Paulo e Bahia e da Contra Costa da África, da região de Moçambique (os Macuas e Anjicos, principalmente), o direcionamento é para o centro do Brasil (Goiaz e Minas Gerais) São Paulo e Rio Grande do Sul. Da Baía do Benin, no Golfo da Guiné, serão retirados as últimas levas de seres humanos Jeje-Mina; 
É importante destacar que as populações africanas sub-saariana não foram responsáveis somente pela ocupação efetiva do território brasileiro e pela mão-de-obra, eles marcaram e marcam, de forma irreversível, a nossa formação social, tecnológica, demográfica e cultural que, ao longo desses séculos, foi preservada e recriada, mesmo com as políticas contrárias do sistema. Vários setores da população brasileira contemporânea são vítimas de discriminação e preconceitos de toda a ordem. Entre os tipos de discriminação, a étnica, que atinge particularmente o contingente de ascendência africana no país, é sem dúvida a de maior extensão social e territorial, devido à grande expressão demográfica. Os problemas se revelam já quando se quer saber qual o número real de "negros" ou da população de ascestralidade na África. É importante lembrar que a palavra "negro" tem historicamente um significado pejorativo, de algo ruim, que não é humano, mas associado a animal. Esse é um ponto de esclarecimento e correção histórica necessária e que requer uma ação política e educacional consequente, até porque, está incorporado de forma secular no pensamento social brasileiro. Se não fossem os negreiros e seus navios, comerciantes de seres humanos escravizados no continente africano, não existiria o "negro" e a "negra", tratados como mercadoria. Daí vem a "invenção" e promoção do engano secular denominado "raça negra".

A questão demográfica do "Brasil africano" tem ficado historicamente sem resposta adequada, isto porque os critérios de aferição racial oficiais levam à subestimação do numero real de cidadãos de matriz afro-brasileira que integram o país. O Instituto Brasileiro de Geografia e Estatística (IBGE) tem agrupado os indivíduos em brancos, pretos, amarelos e pardos, considerando brancos, pretos ou amarelos os que assim se declararem e os "outros" ficam classificados como pardos. A representaçao cartográfica da população recenseada como "preta" no Censo Demográfico realizado em 2000 pelo IBGE, nos revela a presença expressiva dessa população no país, destacando, principalmente que o Brasil urbano, peri-urbano e rural é significativamente afro-brasileiro. Existem evidências de que o contingente populacional brasileiro de matriz africana não é minoria e essa é mais uma estratégia do sistema de classificar os grupos discriminados de minorias, fazendo supor que estes atingem um número de pessoas menor que o de fato, utilizando-se de artifícios numéricos.

Se fizermos uma simulação e juntarmos as populações recenseadas pelo IBGE como "preta" e "parda" do Brasil no ano 2000, teremos 69.649.861 habitantes (47\% do contingente nacional). Não podemos perder de vista o que nos lembra o ditado popular: "de noite todos os gatos são pardos". Ou seja, associado ao "pardo" esta a indefinição da sua identidade, do seu lugar na sociedade, da sua referência ancestral, em síntese, da sua territorialidade. São milhares de homens, mulheres, crianças e idosos que sentem internamente, que não existe, ainda, um lugar definido na estrutura social do país. Por ser um contingente populacional oriundo de um processo secular de "mistura" étnica, as relações de valor que foram associados, sistematicamente, aos povos europeus, como o "modelo" de referência e aceito pelo sistema dominante, imprimem vários desajustes nas formas de pensar, de se inserir e de se enquadrar na sociedade brasileira. Se assumirmos que a população considerada como "parda" nesse Censo é de fato uma população mestiça que tem graus diferenciados de ascendência africana, ficará evidente que a população do Brasil com referência no continente africano não é minoria. 


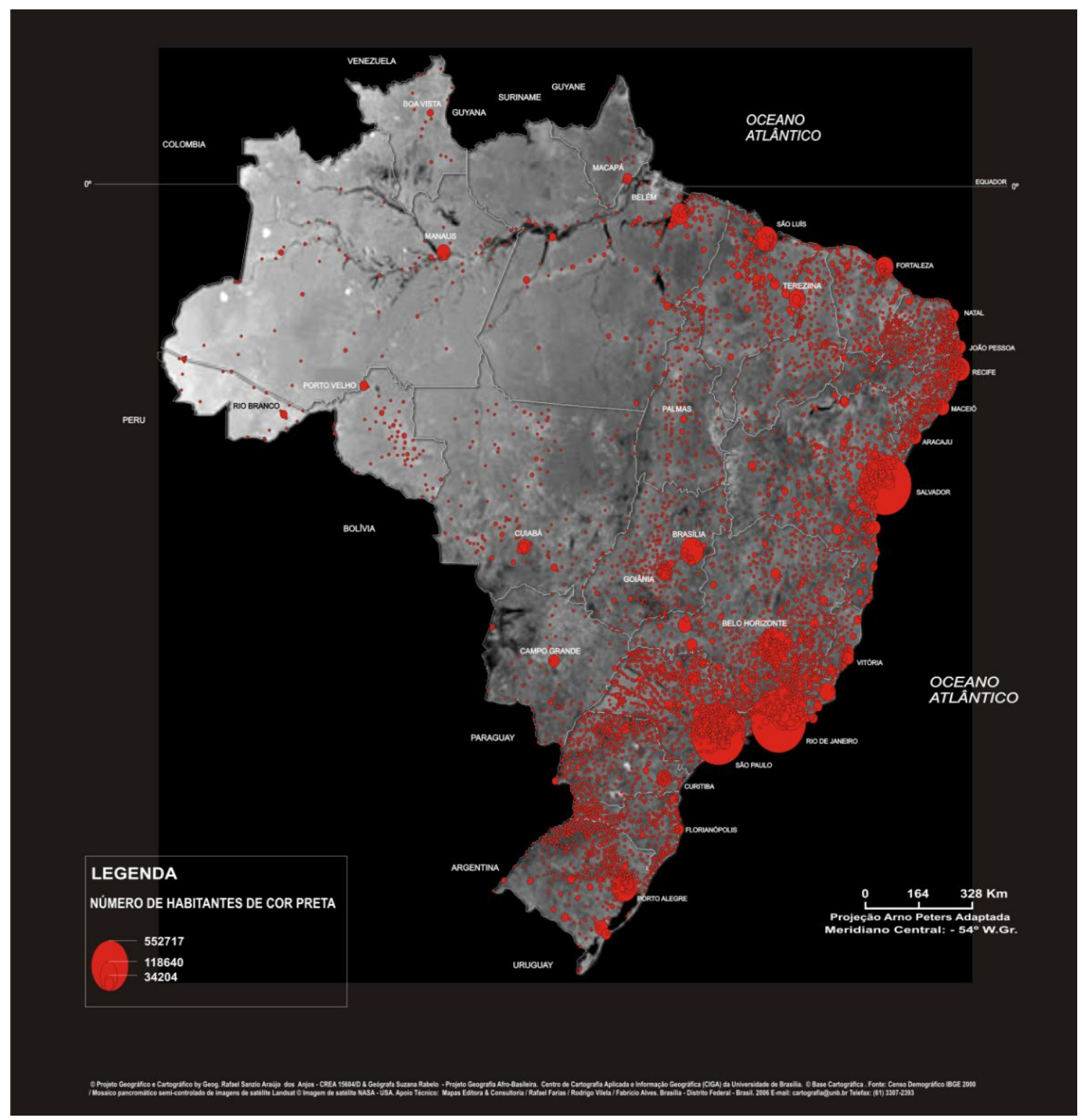

Figura 6 - Distribuição da população caracterizada como preta por Município - IBGE -CENSO 2010

A cartografia da população contemporânea de matriz africana, mostra a expansão e a consolidação do "Brasil Africanizado" em toda a sua extensão continental. A predominância da matriz Bantu, expressão que significa "as pessoas" ou "seres humanos", revela a sua importância na nossa formação cultural e identitária. Ao longo do século XX vai ficar mais evidenciado os registros das distintas línguas africanas no país, constituindo o fato mais importante da transformação da língua portuguesa, sobretudo as marcas significativas das sociedades oriundas da grande bacia do rio Congo e das regiões do extenso Golfo da Guiné, com influência expressiva no nosso linguajar cotidiano. Algumas expressões de origem Bantu, por exemplo, continuam bem integradas e presentes no nosso cotidiano como: carimbo, quitanda, corcunda, caçula, cachaça, cachimbo, canjica, capanga, dendê, dengo, fubá, ginga, macaco, gangorra, macumba, maculêlê, minhoca, molque, quiabo, dentre outras, constituem uma pequena mostra do português afro-brasileiro (CASTRO, 2001). 


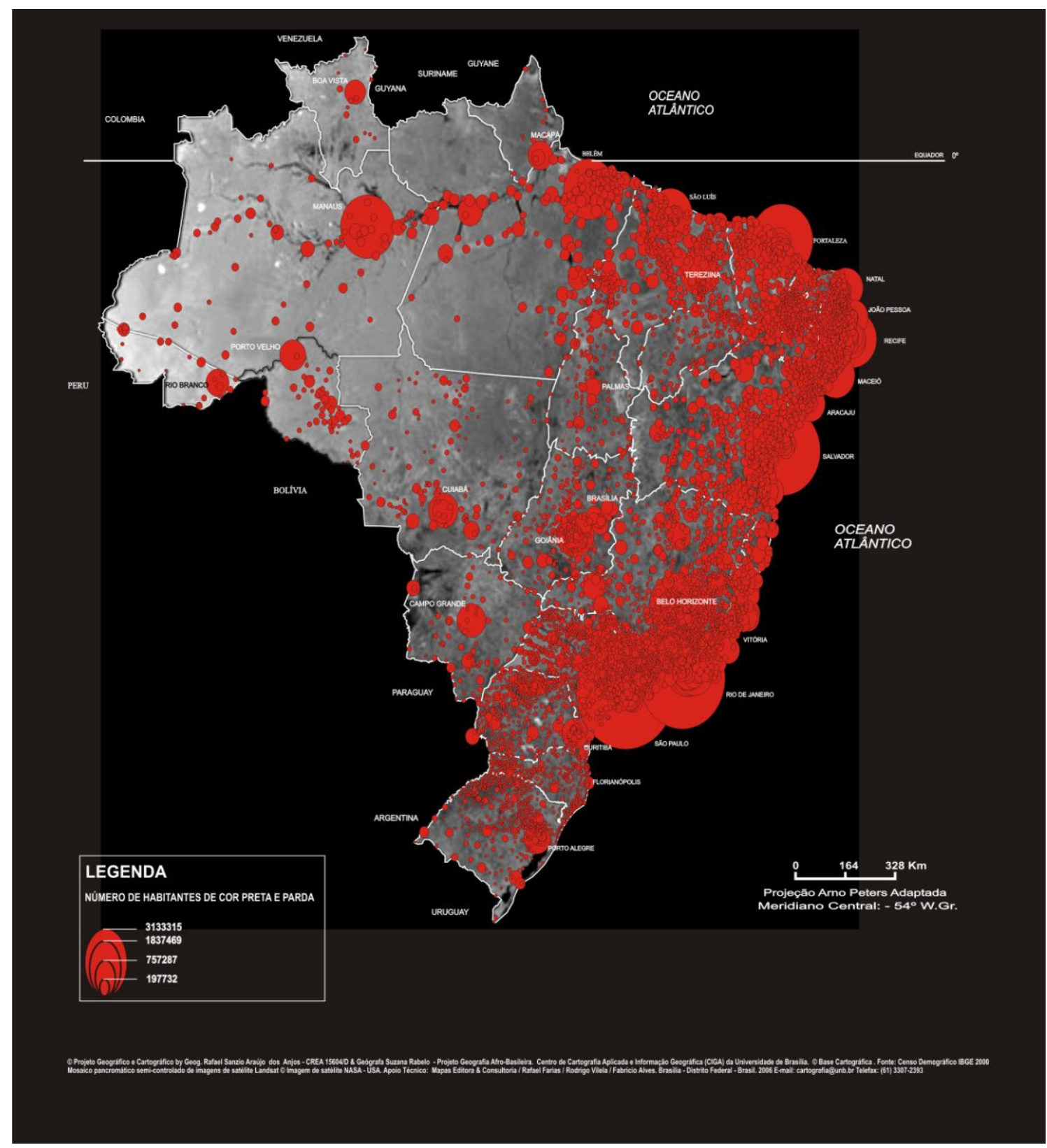

Figura 7 - Distribuição da população caracterizada como preta e parda por município - IBGE - CENSO 2000

As estatísticas apontam o Brasil como a segunda maior nação negra do planeta e é com relação a essa população que são computadas as estatísticas mais discriminatórias e de depreciação socioeconômica. Nos piores lugares da sociedade e do território, com algumas exceções, estão as populações afro-brasileiras. Não é possível mais esconder que temos diferenças sociais, econômicas, territoriais seculares e estruturais, para as quais os "remédios" ainda estão chegando e os assuntos são empurrados para um outro dia, para a próxima semana, no mês que vem, no próximo ano, que nunca chega. E os séculos estão passando!

Dessa maneira, ser descendente do continente africano no Brasil, secularmente continua sendo um fator de risco, um desafio para manutenção da sobrevivência humana, um esforço adicional para ter visibilidade no sistema dominante e, sobretudo, colocar uma energia adicional para ser - estar inserido. É uma luta secular contra a exclusão territorial, social e econômica. 


\section{CONSIDERAÇÕES FINAIS}

Considerando-se que as construções analíticas e as especulações não se esgotaram, concluímos e recomendamos o seguinte:

- A questão do desconhecimento da população brasileira no que se refere ao continente africano é um entrave para uma perspectiva real de democracia racial no país. Não podemos perder de vista que entre os principais obstáculos criados pelo sistema a inserção da população de matriz africana na sociedade brasileira, está a inferiorização desta no ensino. Esse contexto somente poderá mudar com uma política educacional mais agressiva e com o foco direcionado para desmistificar o continente africano para a população do Brasil. O brasileiro não pode mais ficar achando que a África é um país; nem tão pouco achar que somente existem doenças; seres humanos e culturas primitivas; espaços para safári e animais exóticos, etc. $\mathrm{O}$ dano principal dessa informação errônea é auxiliar na manutenção de uma população preconceituosa às referências africanas e ser feita uma associação imediata aos afro-brasileiros e afro-brasileiras. Este é um ponto estrutural para um processo de mudança, onde o ser humano brasileiro de ascendência africana seja, de fato, mais respeitado no sistema. Uma parte grande do problema, continua sendo, a desinformação, ou seja, a posição da África, geralmente um dos últimos continentes nos compêndios escolares e oficiais, precisa ser alterado;

- Outro ponto estrutural, ainda dirigido ao setor decisório do país, se refere à criação das condições necessárias para a realização de um censo demográfico mais realista e que retrate melhor a diversidade étnica brasileira. Este tema é complexo, porque significa mudar os métodos de aferição da população e, por conseguinte, a possibilidade de registro oficial de um "Brasil Africano"até então sem evidência. Acreditamos, caso exista prioridade política, que ainda é possível uma revisão dos procedimentos metodológicos dos Censos Demográficos oficiais, que poderia incorporar os avanços já conquistados nas centenas de experiências de Censos Étnicos Escolares já realizados por professores e diretores de escolas da nação. Um componente estrutural neste processo são os programas educacionais de conscientização e esclarecimento das matrizes étnicas de formação e sustentação do Brasil.;

- É importante não perder de vista que vivemos o momento histórico de redefinição de uma identidade no país para os afro-brasileiros. Este processo de inclusão social constitui um desafio para as duas partes: um Brasil "maquiado de Europa" que está sendo pressionado para mudar, para incluir, para reconhecer cidadanias e direitos históricos de outras matrizes culturais e étnicas e, do outro lado a "África brasileira”, secularmente excluída, aflorando os seus conflitos internos, buscando formas eficazes de diálogo com o sistema e com o desafio de minorar o "medo" do "Brasil europeu" de que não vamos lhe tomar o Brasil. Podemos conviver com menos hipocrisia, mais respeito pelas diferênças e equilíbrio sócio-econômico!

- Acreditamos no processo educacional como um elemento de transformação e de reconstrução dos conteúdos e informações errôneas, assim como a visibilidade na sociedade civil, como ferramentas para ampliação do conhecimento e minorar o preconceito. Neste sentido, algumas atividades itinerantes, como as Exposições Geográfica-Cartográfica: A África, o Brasil e os Territórios dos Quilombos e, mais recentemente, a mostra O Brasil Africano: Diáspora-Quilombos-Território-População, assim como, as Oficinas Temática: Matrizes Africanas do Território Brasileiro e A África, o Brasil e os Quilombos: Heranças Geográficas, são eventos educacionais que têm buscado uma maior visibilidade espacial e junto aos educadores e estudantes, para essas questões geográficas estruturais da formação étnica do país. Outro segmento importante são as publicações com toda a documentação cartográfica e historiográfica das comunidades quilombolas (2000, 2005, 2006 e 2009) e os volumes da Coleção África-Brasil: 
Cartografia para o Ensino-Aprendizagem (2005 e 2007), que constituem um conjuntos vários mapas temáticos para auxiliar o professor a transmitir informações sobre a Geografia da África e a Geografia Afro-Brasileira. Outras informações do Projeto Geografia Afro-Brasileira: Educação \& Planejamento do Território e desses produtos podem ser acessadas no site www. ciga.unb.br e www.rafaelsanziodosanjos.com.br

- Tomamos como premissa que as informações por si só não significam conhecimento. Entretanto, elas nos revelam que com o auxílio da ciência e da tecnologia, que temos condições de colaborar na modificação das políticas pontuais e superficiais a fim de subsidiar a adoção de medidas concretas para alteração, de forma estrutural, das situações das populações do "Brasil Africano".

\section{REFERÊNCIAS BIBLIOGRÁFICAS}

ANJOS, R. S. A. A utilização dos recursos da cartografia conduzida para uma África desmistificada. Revista Humanidades. Brasília: Editora Universidade de Brasília, 6 (22): 12-32, 1989.

ANJOS, R. S. A. A geografia, os negros e a diversidade cultural. Série O Pensamento Negro em Educação - Núcleo de Estudos Negros. Florianópolis: 1998. p. 93-106

ANJOS, R. S. A. A geografia, a África e os negros brasileiros. In: MUNANGA, K. (org.). Superando o racismo na escola. Brasília: Ministério da Educação, Secretaria de Educação Fundamental, 1999. p. 169-182.

ANJOS, R. S. A. Distribuição espacial das comunidades remanescentes de quilombos do Brasil. Revista Humanidades. Brasília: Editora Universidade de Brasília, 9 (47): 87-98, 1999.

ANJOS, R. S. A. A África, a geografia, o tráfico de povos africanos e o Brasil. Revista Palmares em Ação. Brasília: Fundação Cultural Palmares - MINc. Ano 1 No.2 : 56-66, 2002

ANJOS, R. S. A. Coleção África-Brasil: Cartografia para o ensino-aprendizagem. Brasília: Mapas Editora \& Consultoria, 2a . Edição. 2005 - BsB - DF.

ANJOS, R. S. A. Territórios das comunidades remanescentes de antigos quilombos no Brasil - Primeira configuração espacial. Brasília: Mapas Editora \& Consultoria, 3a . Edição. 2005 - BsB - DF.

ANJOS, R. S. A. Territórios das comunidades quilombolas do Brasil - Segunda configuração espacial. Brasília: Mapas Editora \& Consultoria. 2005 - BsB - DF.

ANJOS, R. S. A. Geografia, território étnico e quilombos. In: GOMES, N. L. (org.). Tempos de lutas: as ações afirmativas no contexto brasileiro. Brasília: MEC-Secad, 2006. p.81-103.

ANJOS, R.S.A \& CYPRIANO, A. Quilombolas - tradições e cultura da resistência. Aori Comunicações. São Paulo: Petrobras, 2006. 240 p.

ANJOS, R.S.A. Coleção África-Brasil: Cartografia para o ensino-aprendizagem. Volume II Brasília: Mapas Editora \& Consultoria, Brasília, 2007.

ANJOS, R. S. A. Cartografia \& Educação. Volume I Brasília: Mapas Editora \& Consultoria, Brasília, 2007. ANJOS, R. S. A. África-Quilombos-Brasil: Átlas Geográfico. Relatório Final de Pós-Doutorado em Cartografia Étnica. Universidade de Brasília - GEA - CIGA / CNPQ / Museu Real da África Central MRAC - Tervuren. Bruxelas - Bélgica, 2008.

ANJOS, R. S. A. Quilombos: Geografia Africana-Cartografia Étnica-Territórios Tradicionais. Mapas Editora \& Consultoria, 190p. Brasília, 2009.

ANJOS, R. S. A . Territorialidade Quilombola: Fotos \& Mapas / Quilombola Territoriality: Photos \& Maps. Mapas Editora \& Consultoria., 124 p. Brasília, 2011.

CARRIL, L. F. B. Territórios negros: comunidades remanescentes de quilombos no Brasil. AGB Informa no.67. São Paulo,1997. p. 6-7. 
CASTRO, Y. P. Falares africanos na Bahia - um vocabulário afro-brasileiro. Academia Brasileira de Letras. Rio de Janeiro: Topbooks, 2001. 366p.

IBGE. Pesquisa Nacional por Amostra de Domicílio. Rio de Janeiro: IBGE - PNAD, 1996

MELO, A. Setenta e cinco por cento dos escravos levados para o Brasil eram Bantu. Jornal de Angola, 10/9/2008. Luanda - Angola.

MINISTÉRIO DA SAÚDE. Saúde da população negra no Brasil - Contribuições para a promoção da equidade. Brasília: MS, 2004 .

Trabalho enviado em agosto de 2011 Trabalho aceito em outubro de 2011 